\title{
Avaliação físico-química e microbiológica de fitoterápicos utilizados em uma
}

\section{farmácia municipal de manipulação}

\author{
Physical, chemical and microbiological evaluation of herbal drugs used in a municipal pharmacy of \\ manipulation
}

Evaluación físico-química y microbiológica de medicamentos herbarios utilizados en una farmacia municipal de manipulación

\begin{abstract}
Resumo
O medicamento fitoterápico possui como insumo, plantas medicinais ou seus derivados. Apesar de inúmeros benefícios, o uso indiscriminado e falhas durante a produção podem expor o consumidor final a efeitos nocivos à sua saúde. Nesse sentido, o estudo avaliou a qualidade físico-química e microbiológica de insumos vegetais utilizados em uma farmácia de manipulação municipal na região sudoeste do Paraná. Foram analisadas amostras de extratos secos de: Cymbopogon citratus, Baccharis trimera., Aesculus hippocastanum, Equisetum arvense, Echinodorus grandiflorus, Curcuma longa, Ginkgo biloba, Piper methysticum, Melissa officinalis e Passiflora incarnata. Para a avaliação físico-química, foram realizados os testes, segundo a Farmacopeia Brasileira (2019): características organolépticas, umidade, granulometria, $\mathrm{pH}$, densidade, solubilidade e constituintes secundários, dentre os quais flavonoides, saponinas e taninos. Para a análise microbiológica, determinou-se a presença de microrganismos totais, bolores, leveduras, Salmonella sp e Shiguella sp, segundo Barbosa (2014). A avaliação organoléptica revelou que todas as amostras se apresentaram com aspecto de pó fino e homogêneo, com odor e cor característicos de cada espécie. Os extratos secos apresentaram resultados de teor de umidade, granulométricos, $\mathrm{pH}$ e densidade dentro dos valores de referência farmacopéicos. Com relação a solubilidade, a amostra de E. arvense se revelou praticamente insolúvel ao solvente utilizado. Todas as amostras testaram positivo para a presença de flavonoides. As amostras de G. biloba, P. methysticum e P. incarnata não apresentaram saponinas. Nenhuma amostra apresentou contaminação por bactérias totais, Salmonella sp e Shiguella sp. Portanto, os resultados obtidos nesta pesquisa atendem aos parâmetros da legislação vigente, comprovando a qualidade dos extratos estudados.
\end{abstract}

Palavras-chave: Controle de qualidade; Plantas medicinais; Fitoterápicos. 


\begin{abstract}
The herbal medicine has medicinal plants or their derivatives as input. Despite numerous benefits, indiscriminate use and failures during production can expose the end consumer to harmful effects on their health. In this sense, the study evaluated the physical-chemical and microbiological quality of plant inputs used in a municipal pharmacy in the southwestern region of Paraná. Samples of dry extracts from: Cymbopogon citratus, Baccharis trimera., Aesculus hippocastanum, Equisetum arvense, Echinodorus grandiflorus, Curcuma longa, Ginkgo biloba, Piper methysticum, Melissa officinalis and Passiflora incarnata were analyzed. For the physical-chemical evaluation, the tests were carried out, according to the Brazilian Pharmacopoeia (2019): organoleptic characteristics, humidity, granulometry, $\mathrm{pH}$, density, solubility and secondary constituents, among which flavonoids, saponins and tannins. For the microbiological analysis, the presence of total microorganisms, molds, yeasts, Salmonella sp and Shiguella sp was determined, according to Barbosa (2014). The organoleptic evaluation revealed that all samples were presented with a fine and homogeneous powder aspect, with a characteristic odor and color of each species. The dry extracts showed results of moisture content, particle size, $\mathrm{pH}$ and density within the pharmacopoeic reference values. Regarding solubility, the E. arvense sample proved to be practically insoluble in the solvent used. All samples tested positive for the presence of flavonoids. The samples of G. biloba, P. methysticum and P. incarnata did not present saponins. No sample showed contamination by total bacteria, Salmonella sp and Shiguella sp. Therefore, the results obtained in this research meet the parameters of the current legislation, proving the quality of the studied extracts.
\end{abstract}

Keywords: Quality control; Medicinal plants; Herbal medicines.

\title{
Resumen
}

La fitoterapia tiene como insumo plantas medicinales o sus derivados. Apesar de los numerosos beneficios, el uso indiscriminado y los fallos durante la producción pueden exponer al consumidor final a efectos nocivos para su salud. En este sentido, el estudio evaluó la calidad físico-química y microbiológica de insumos vegetales utilizados en una farmacia municipal en el suroeste de Paraná. Se analizaron muestras de extractos secos de: Cymbopogon citratus, Baccharis trimera, Aesculus hippocastanum, Equisetum arvense, Echinodorus grandiflorus, Curcuma longa, Ginkgo biloba, Piper methysticum, Melissa officinalis y Passiflora incarnata. Para la evaluación físico-química, se realizaron las pruebas, según la Farmacopea Brasileña (2019): características organolépticas, humedad, granulometría, pH, densidad, solubilidad y constituyentes secundarios, entre los que se encuentran flavonoides, saponinas y taninos. Para el análisis microbiológico se determinó la presencia de microorganismos totales, mohos, levaduras, Salmonella sp y Shiguella sp, según Barbosa (2014). La evaluación organoléptica reveló que todas las muestras se presentaron con un aspecto de polvo fino y homogéneo, con un olor y color característico de cada especie. Los extractos secos mostraron resultados de contenido de humedad, tamaño de partícula, $\mathrm{pH}$ y densidad dentro de los valores de referência farmacopeicos. En cuanto a la solubilidad, la muestra de E. arvense resultó ser prácticamente insoluble en el disolvente utilizado. Todas las muestras dieron positivo a la presencia de flavonoides. Las muestras de G. biloba, $P$. methysticum y P. incarnata no presentaron saponinas. Ninguna muestra mostró contaminación por bacterias totales, Salmonella sp y Shiguella sp. Por tanto, los resultados obtenidos en esta investigación cumplen con los parámetros de la legislación vigente, lo que acredita em la calidad de los extractos estudiados.

Palabras clave: Control de calidad; Plantas medicinales; Hierbas medicinales.

\section{Introdução}

O Brasil apresenta uma notável diversidade de espécies vegetais, dentre as quais muitas apresentam importante potencial terapêutico. A riqueza da flora brasileira se dá em razão dos diversos biomas que compõem este território. Neste país detentor de um imensurável potencial no que se refere a plantas medicinais, a sabedoria popular complementa o conhecimento científico, aprimorando os cuidados quanto ao manejo e utilização destes recursos (Rodrigues et al., 2020).

De acordo com Haraguchi et al. (2020), o medicamento fitoterápico diz respeito ao produto que possui como insumo as plantas medicinais ou seus derivados, com exceção daqueles que apresentam substâncias ativas isoladas. Em complemento, a fitoterapia entendida como uma das Práticas Integrativas e Complementares (PIC) no Sistema Único de Saúde (SUS) corresponde a utilização de plantas medicinais nas mais variadas formas farmacêuticas incluindo o uso dos fitoterápicos (Badke et al., 2019). Dentre as plantas medicinais com importante atividade terapêutica e que são amplamente utilizadas pela população destacam-se Cymbopogon citratus (DC.) Stapf., Baccharis trimera (Less) DC., Aesculus hippocastanum L., Equisetum arvense L., Echinodorus grandiflorus (Cham. \& Schltdl.) Micheli, Curcuma longa L., Ginkgo biloba L., Piper methysticum G. Forst., Melissa officinalis L. e Passiflora incarnata L.

O Cymbopogon citratus (DC.) Stapf pertence à família Poaceae, é popularmente conhecido como capim-limão, 
capim-cidró ou capim-cidreira. Esta planta é utilizada na medicina tradicional como um importante calmante e antiespasmódico, apresentando ainda atividade antimicrobiana (Lorenzetti et al., 2012).

A Baccharis trimera (Less) DC., popularmente chamada de carqueja, é uma planta perene, da família Asteraceae, facilmente encontrada em todos os biomas brasileiros, visto que é capaz de se desenvolver, nos mais diversos tipos de solo encontrados no país. Dentre os principais componentes da carqueja se destacam os flavonoides, triterpenos, ácidos cumarínicos, sesquiterpenos e fenilpropanóides, os quais são responsáveis por seus importantes efeitos farmacológicos diuréticos, digestivos, anti-reumáticos, analgésicos, anti-inflamatórios e hepatoprotetores (Capra, 2014).

A Aesculus hippocastanum L. (família Sapindaceae) corresponde a uma árvore robusta popularmente conhecida como castanheiro-da-índia (Colson et al., 2019). Os extratos de suas sementes que são chamadas de castanha-da-índia, são utilizados há muitos séculos com fim terapêutico, sendo especialmente empregadas no tratamento de insuficiência venosa crônica, ulcerações, queimaduras e tratamento de inflamações na pele (Bonomo et al., 2020).

A Equisetum arvense L., da família Equitaceae, comumente chamada de cavalinha, apresenta importantes ações diuréticas, anti-inflamatórias e adstringentes, podendo ser associada no tratamento de hipertensão arterial. Dentre os seus constituintes químicos, se destacam o óleo essencial, cumarinas, alcaloides, pigmentos e mucilagens (Ogava et al., 2003).

A espécie vegetal Echinodorus grandiflorus (Cham. \& Schltdl.) Micheli, da família Alismataceae é popularmente conhecida como chapéu-de-couro ou ainda erva-do-brejo, sendo encontrada em grande parte do continente americano. Apresenta alcaloides, diterpenoides, taninos, saponinas e flavonoides que asseguram ações anti-hipertensivo, hipolipemiante e diurético (Carvalho et al., 2019).

A cúrcuma (Curcuma longa L.) da família Zingiberaceae, tem seu uso largamente empregado à gastronomia, visto que corresponde a uma especiaria que colabora para dar sabor e colorir diversos alimentos. Por outro lado, apresenta potencial biológico anti-inflamatório, assim como a proteção contra disfunção cardiovascular, câncer e diabetes (Cortez et al., 2020).

O Ginkgo biloba L. faz parte da família Ginkgoaceae, seu extrato apresenta ação anti-inflamatória, antioxidante e ainda dispõe de efeitos sobre a hipoperfusão cerebral crônica, função cognitiva e prevenção do apoptose (Wang et al., 2020).

A Piper methysticum G. Forst. (família Piperaceae), é popularmente conhecida como kava-kava e apresenta ações sobre o sistema nervoso central, sendo ansiolíticas, sedativas, anticonvulsivantes, anestésicas locais e ainda espasmolíticas (Nowacki et al., 2015).

A Passiflora incarnata L., da família Passifloraceae, comumente chamada de maracujá, tem seu uso difundido popularmente e apresenta grande interesse pela indústria alimentícia e cosmética, nos últimos anos houve um aumento significativo da sua aplicabilidade. Seu uso é associado à ação antidiabética, ansiolítica e sedativa e se destacam os seus efeitos antiespasmódicos e analgésicos (Sarto et al., 2018).

A Melissa officinalis L. pertencente à família Lamiaceae, é popularmente conhecida como melissa ou erva-cidreira. É uma planta aromática, tem seu uso difundido popularmente e apresenta propriedades espasmolíticas, antioxidantes, antivirais e antimicrobianas (Silva et al., 2018). No extrato da melissa destaca-se, o efeito ansiolítico (Miraj; Kopaei; Kiani, 2016).

As plantas medicinais podem ser expostas a diferentes contaminantes em diversos momentos da cadeia produtiva. Nesse sentido, independentemente da origem desse insumo vegetal que pode ser nativo ou cultivado, existem fragilidades quanto à contaminação por fungos principalmente (Hellmann; Velasquez, 2017).

De acordo com Hellmann e Velasquez (2017), os microrganismos identificados em amostras vegetais podem ser estritamente patógenos ou ainda a carga microbiológica da alíquota pode ser superior ao indicado na legislação pertinente.

Vislumbra-se a importância de um rigoroso controle de qualidade da droga vegetal, a qual é compreendida como a planta medicinal ou suas partes que apresentem substâncias com efeito terapêutico principalmente após o período entre a colheita e o processamento. De acordo com a legislação pertinente, ao se realizar o controle de qualidade físico, químico e 
microbiológico da matéria-prima, devem-se adotar as referências presentes em farmacopeias validadas pela ANVISA. Em sua ausência podem ser utilizadas descrições presentes em outras documentações técnico-científicas ou laudos emitidos por profissionais habilitados (Brasil, 2014).

Diante do exposto, o presente estudo apresentou as características de qualidade físico-química e microbiológica dos insumos vegetais utilizados como matéria-prima em uma farmácia de manipulação público-privada na região do sudoeste do Paraná. Além disso, o presente estudo será capaz de contribuir para o aperfeiçoamento de práticas adotadas durante os testes de controle de qualidade de extratos secos de plantas medicinais.

\section{Metodologia}

Trata-se de uma pesquisa laboratorial, de natureza qualitativa, onde foram analisadas amostras de extratos secos de Cymbopogon citratus (capim-limão), Baccharis trimera (carqueja), Aesculus hippocastanum (castanha-da-índia), Equisetum arvense (cavalinha), Echinodorus grandiflorus (chapéu-de-couro), Curcuma longa (cúrcuma), Ginkgo biloba (ginkgo), Piper methysticum (kawa-kawa), Melissa officinalis (melissa) e Passiflora incarnata (passiflora), adquiridas de março a abril de 2020.

\subsection{Avaliação físico-química}

A avaliação físico-química foi realizada no Laboratório Municipal de Manipulação de Fitoterápicos localizado na Universidade Paranaense - Francisco Beltrão. Os testes realizados foram: aspecto, cor, odor, umidade, granulometria, determinação do potencial hidrogeniônico, densidade e solubilidade. Também foram realizadas as pesquisas de flavonoides, taninos e saponinas.

Os testes foram executados em triplicata e seguiram as metodologias preconizadas pela Sociedade Brasileira de Farmacognosia (2020) e pela Farmacopeia Brasileira (BRASIL, 2019).

\subsection{Avaliação microbiológica}

As análises microbiológicas foram realizadas no Laboratório de Microbiologia da Universidade Paranaense UNIPAR, campus Francisco Beltrão/PR. Foi adicionado uma grama da amostra a $9 \mathrm{~mL}$ de solução salina e realizadas diluições seriadas nas proporções 1:10 (101); 1:100 (102), 1:1000 (103), 1:10.000(104) e 1:100.000 (105) a fim de avaliar a presença de bolores e leveduras, microrganismos totais, Salmonella sp e Shiguella sp, seguindo a metodologia proposta por Barbosa et al. (2014).

Cada diluição foi semeada em duplicata em placas de petri contendo os meios de cultura Agar Batata Dextrose (BDA/Himedia), para pesquisa de bolores e leveduras, Plate Count Agar (PCA/Himedia) para determinação de microrganismos totais e Ágar Salmonella Shiguella (SS/Acumedia) para avaliar a presença de Salmonella sp e Shigella sp. As placas foram incubadas em estufa por $24 / 48$ horas a $37^{\circ} \mathrm{C}$.

\section{Resultados e Discussão}

As características organolépticas dos extratos secos das amostras de capim-limão, carqueja, castanha-da-índia, cavalinha, chapéu-de-couro, cúrcuma, ginkgo, kava-kava, melissa e passiflora apresentaram aspecto de pó fino e homogêneo, com cor e odor característicos. 
Tabela 1: Características organolépticas das amostras.

\begin{tabular}{cccc}
\hline \multirow{2}{*}{ Amostra } & \multicolumn{3}{c}{ Parâmetros } \\
\cline { 2 - 4 } & Aspecto & Cor & Odor \\
\hline Capim-limão & Pó fino, homogêneo & Marrom claro & Característico \\
\hline Carqueja & Pó fino homogêneo & Verde claro & Característico \\
\hline Castanha-da-índia & Pó fino, homogêneo & Bege & Característico \\
\hline Cavalinha & Pó fino, homogêneo & Esverdeado & Característico \\
\hline Chapéu-de-couro & Pó fino, homogêneo & Marrom esverdeado & Característico \\
\hline Cúrcuma & Pó fino, homogêneo & Amarelo alaranjado & Característico \\
\hline Ginkgo & Pó fino, homogêneo & Marrom & Característico \\
\hline Kava-kava & Pó fino, homogêneo & Amarelo esverdeado & Característico \\
\hline Melissa & Pó fino, homogêneo & Marrom claro & Característico \\
\hline Passiflora & Pó fino, homogêneo & Marrom escuro & Característico \\
\hline
\end{tabular}

Fonte: Autores.

Melo et al. (2007) encontraram características organolépticas semelhantes às do presente estudo para amostras de capim-limão e castanha-da-índia, as quais se apresentaram com variações de marrom-claro a marrom-escuro e de marrom a verde-escuro, respectivamente.

Em estudo realizado por Melo et al. (2007) para verificar a qualidade de produtos a base de capim-limão e castanhada-índia, verificou-se a presença de informações técnico-científicas em rótulos e bulas, bem como a autenticidade e a pureza dos produtos. Observou-se que todas as amostras foram identificadas como autênticas, porém não apresentavam informações completas e satisfatórias nas embalagens dos produtos finais. Da mesma forma, Pereira (2016) registrou que em amostras comercializadas de E. arvense a quantidade de elementos estranhos respeita os limites estabelecidos pela legislação pertinente. Entretanto, as embalagens não apresentavam informações essenciais ao consumidor, como por exemplo os constituintes químicos da amostra em questão. 
Tabela 2: Análises da umidade, granulometria e $\mathrm{pH}$ das amostras.

\begin{tabular}{cccccccc}
\hline Amostra & \multicolumn{2}{c}{ Umidade (\%) } & \multicolumn{2}{c}{ Granulometria (\%) } & \multicolumn{2}{c}{ pH em sol. Aquosa 10\% } \\
& Especificação Resultado & \multicolumn{2}{c}{ Especificação Resultado } & \multicolumn{2}{c}{ Referência Resultado } \\
Capim-limão & Máx. 5 & 2,00 & Mín. 90 & 91 & $4,0-7,0$ & 5,90 \\
Carqueja & Máx. 6 & 2,00 & Mín. 95 & 96 & $3,0-5,5$ & 5,12 \\
Castanha-da-índia & Máx. 5 & & Mín. 95 & 98 & $4,5-6,5$ & 5,97 \\
Cavalinha & Máx. 5 & 1,70 & - & 92 & $4,0-6,0$ & 6,00 \\
Chapéu-de-couro & Máx. 6 & 3,05 & Mín. 90 & 94 & $4,0-7,0$ & 5,97 \\
Cúrcuma & Máx. 5 & $2,05^{*}$ & Mín. 90 & 92 & - & 5,51 \\
Ginkgo & Máx. 4 & $1,60^{*}$ & 100 & 100 & - & 5,23 \\
Kava-kava & Máx. 5 & $1,20^{*}$ & Mín. 95 & 98 & - & 5,47 \\
Melissa & Máx. 5 & 1,60 & Mín. 95 & 99 & $4,5-6,5$ & 5,82 \\
Passiflora & Máx. 6 & 3,30 & Mín. 90 & 99 & $5,0-6,0$ & 5,23 \\
\hline
\end{tabular}

Valores de referência: Farm. Bras. VI ed., 2019.

$*$ Valores fornecidos pelo fabricante.

Granulometria: Malha $\leq$ 80/orifício de $180 \mu \mathrm{m}$.

Fonte: Autores.

O percentual de umidade dentro do parâmetro máximo permitido atua como fator para diminuição ou inibição do crescimento microbiano, promovendo a estabilidade microbiológica da matéria-prima vegetal (Oliveira; Petrovick, 2010). Nas amostras analisadas, todos os resultados apresentaram-se dentro dos parâmetros estabelecidos pela Farmacopeia Brasileira (2019).

Os resultados obtidos divergem com o estudo no Paraná de Garbin et al. (2013) que avaliaram a qualidade de 25 amostras de espécies vegetais distribuídas à população através de uma Unidade Básica de Saúde, constatando que nenhuma foi aprovada no controle de qualidade microbiológico, teor de umidade e outros parâmetros. Da mesma forma, estudos realizados por Gonçalves (2015) reprovaram amostras comercializadas em estabelecimentos farmacêuticos em São Luís, Maranhão.

Com relação à granulometria, os extratos vegetais apresentaram tamanho médio de partículas dentro dos parâmetros esperados, corroborando com os valores descritos pelos fornecedores. De acordo com Correia (2011), a análise granulométrica da matéria-prima de origem vegetal corresponde a um importante parâmetro para avaliar a sua biodisponibilidade, visto que esta avaliação determina a superfície de contato para interação com o solvente indicando a sua dissolução. Assim, quanto menor a partícula, maior é a sua superfície e maior é a sua dissolução.

Segundo a Tabela 2, os valores de pH em solução aquosa $10 \%$ atendem às especificações recomendadas. Segundo André, Silva e Vasconcelos (2013), o pH é um parâmetro que possui relação direta com o crescimento de microrganismos. A maior parte das espécies de bactérias caracteriza-se como neutrófilas crescendo na faixa de pH compreendida entre 6,0 e 8,0.

Nota-se que os valores de $\mathrm{pH}$ obtidos são pouco favoráveis à contaminação microbiológica, uma vez que todas as alíquotas apresentam caráter fracamente ácido, atendendo aos valores indicados pelos fabricantes dos produtos. Pereira (2016) encontrou resultados semelhantes ao avaliar amostras de cavalinha, onde registrou pH de caráter ácido para esta espécie. 
Tabela 3: Análises da densidade e solubilidade das amostras.

\begin{tabular}{|c|c|c|c|c|}
\hline \multirow[t]{2}{*}{ Amostras } & \multicolumn{2}{|c|}{ Densidade $(\mathrm{g} / \mathrm{mL})$} & \multicolumn{2}{|c|}{ Solubilidade** $(\%)$} \\
\hline & Referência & Resultado & Referência & Resultado \\
\hline Capim-limão & $0,300-0,600$ & 0,350 & solúvel* & muito solúvel \\
\hline Carqueja & $0,300-0,600$ & 0,399 & solúvel* & muito solúvel \\
\hline Castanha-da-índia & $0,300-0,600$ & 0,300 & parcialmente solúvel* & parcialmente solúvel \\
\hline Cavalinha & $0,350-0,900$ & 0,590 & praticamente insolúvel* & praticamente insolúvel \\
\hline Chapéu-de-couro & $0,300-0,600$ & 0,316 & parcialmente solúvel* & parcialmente solúvel \\
\hline Cúrcuma & $0,340 *$ & 0,425 & parcialmente solúvel* & parcialmente solúvel \\
\hline Ginkgo & $0,520 *$ & 0,513 & solúvel* & muito solúvel \\
\hline Kava-kava & - & 0,600 & sarcialmente solúvel* & parcialmente solúvel \\
\hline Melissa & $0,200-0,500$ & 0,200 & parcialmente solúvel* & parcialmente solúvel \\
\hline Passiflora & $0400-0,800$ & 0,470 & parcialmente solúvel* & parcialmente solúvel \\
\hline
\end{tabular}

Valores de referência: Farm. Bras. VI ed., 2019.

* Valores fornecidos pelo fabricante.

** Solvente utilizado: água.

Fonte: Autores.

De acordo com Moreno e Abreu (2019), o preenchimento de um volume predeterminado com uma quantidade medida em massa pode determinar a densidade dos insumos. Esta análise é fundamental para a escolha do tamanho da cápsula que será adotada para a manipulação, bem como a quantidade necessária de princípio ativo e excipientes a serem utilizados, revelando o tamanho das partículas que compõem a amostra estudada. A determinação da densidade de um insumo contribui para que não ocorram falhas relacionadas à concentração do princípio ativo e reduz a possibilidade de prejuízo financeiro por desperdício de matéria-prima.

Quanto a solubilidade dos extratos secos, as amostras de capim-limão, carqueja e ginkgo foram classificadas como muito solúveis à água, enquanto as alíquotas de castanha-da-índia, chapéu-de-couro, cúrcuma, kava-kava, melissa e passiflora revelaram-se que eram parcialmente solúveis, diferentes do extrato de cavalinha que se demonstrou parcialmente insolúvel ao solvente utilizado, conforme a Tabela 3.

De acordo com Lacerda e Lionzo (2011), a solubilidade em água corresponde a um parâmetro fundamental para avaliar a absorção de medicamentos administrados por via oral. Sabe-se que a absorção está envolvida com a biodisponibilidade, a qual pode ser definida como a relação entre a quantidade do composto e a velocidade com que este atinge o sítio de ação.

Quanto aos constituintes das espécies estudadas, foram realizados testes para a determinação da presença de flavonoides, saponinas e taninos nos extratos secos das plantas medicinais e os resultados obtidos estão expressos na Tabela 4. 
Tabela 4: Presença de flavonoides, saponinas e taninos.

\begin{tabular}{ccccc}
\hline \multirow{2}{*}{ Amostras } & \multirow{4}{c}{ Constituintes } \\
\cline { 2 - 5 } & \multirow{2}{*}{ Flavonoides } & Saponinas & Hidrolisáveis & Condensados \\
\hline Capim-limão & Positivo & Positivo & Positivo & Negativo \\
\hline Carqueja & Positivo & Positivo & Positivo & Negativo \\
\hline Castanha-da-índia & Positivo & Positivo & Negativo & Positivo \\
\hline Cavalinha & Positivo & Positivo & Negativo & Positivo \\
\hline Chapéu-de-couro & Positivo & Positivo & Positivo & Negativo \\
\hline Cúrcuma & Positivo & Positivo & Positivo & Negativo \\
\hline Ginkgo & Positivo & Negativo & Negativo & Positivo \\
\hline Kava-kava & Positivo & Negativo & Positivo & Negativo \\
\hline Melissa & Positivo & Positivo & Positivo & Negativo \\
\hline Passiflora & Positivo & Negativo & Positivo & Negativo \\
\hline
\end{tabular}

Valores de referência: Farm. Bras. VI ed., 2019

Fonte: Autores.

Os metabólitos secundários correspondem a um importante grupo de compostos que desempenham funções essenciais para a manutenção da interação entre a planta e o ecossistema. Esses metabólitos podem apresentar ação farmacológica e atuam como aliados do homem na busca pelo restabelecimento e manutenção da saúde. Entre os compostos oriundos do metabolismo secundário destacam-se os flavonoides, as saponinas e os taninos (Sofiati, 2009).

Todas as amostras apresentaram-se positivas para a presença de flavonoides. De acordo com Sofiati (2009), os flavonoides apresentam efeitos anti-inflamatórios, antialérgicos, vaso protetores, antiulcerogênicos e antiviral.

A pesquisa de saponinas resultou positiva para os extratos de capim-limão, carqueja, castanha-da-índia, cavalinha, chapéu-de-couro, cúrcuma e melissa e apresentou resultado negativo nas amostras de ginkgo, kava-kava e passiflora. Segundo Sofiati (2009), as saponinas dispõem de atividades hipocolesterolemiantes, anti-inflamatórias, anti-helmínticas e antivirais, as quais conferem uso terapêutico para as referidas plantas.

$\mathrm{Na}$ investigação de taninos, todas as amostras apontaram a presença desse metabólito. Os taninos são empregados comumente contra disfunções como a diarreia, hipertensão, reumatismo, hemorragia e feridas, apresentando ação bactericida, fungicida, antiviral e antitumoral (Sofiati, 2009).

Estes achados se assemelham ao registrado por Uzomba, Obinna e Amaralam (2020), que investigaram os componentes fitoquímicos da kava-kava, apontando a presença de flavonoides e taninos e a ausência de saponinas.

Os resultados reforçam Pereira (2016) que avaliou a qualidade de amostras de cavalinha, identificando a presença de flavonoides, saponinas e taninos. Em complemento, durante a realização do seu trabalho que tratava sobre a qualidade de produtos a base de plantas medicinais, Melo et al. (2007) encontraram esses metabólitos secundários em amostras de capimlimão e castanha-da-índia.

A avaliação bacteriológica registrou que todas as amostras apresentaram uma contagem inferior a 10 UFC/g para bactérias totais e não houve crescimento de Salmonella sp e Shiguella sp em nenhuma análise realizada, caracterizando a ausência desses microrganismos, demonstrando que todas as amostras atendem aos valores preconizados pela Farmacopeia Brasileira (2019).

Segundo Braz et al. (2015) a presença de contaminantes microbiológicos, quando superior aos limites estabelecidos 
pela legislação vigente, pode ocasionar riscos para o consumidor uma vez que muitos desses microrganismos apresentam potencial patogênico ao homem, como por exemplo a Salmonella sp e Shigella sp. Estes patógenos podem causar a alteração das características químicas dos compostos resultantes do metabolismo vegetal, podendo diminuir a eficácia farmacológica ou mesmo levar à formação de substâncias tóxicas.

Além da pesquisa de bactérias, foi avaliada a contaminação dos extratos por fungos e todas as amostras analisadas obtiveram valores inferiores a $103 \mathrm{UFC/g}$, obedecendo os parâmetros exigidos pela legislação vigente.

Beltrame et al. (2009) avaliaram o controle de qualidade de amostras comerciais de carqueja no estado do Paraná e revelaram a presença de microrganismos patogênicos e a grande variação de seus componentes químicos, contrastando com os resultados das análises microbiológicas encontrados no presente estudo, que atenderam os parâmetros exigidos.

Nota-se ainda que os resultados obtidos com a análise microbiológica se contrapõem aos registros de Montes et al. (2017), que apresentaram a presença de bactérias totais e fungos em amostras de capim-limão, cavalinha e melissa. Este estudo apontou que das 20 amostras de drogas vegetais dessecadas analisadas, 19 estavam fora dos padrões microbiológicos, não atendendo as exigências mínimas para o consumo humano.

\section{Conclusão}

Com o aumento da procura e utilização de plantas medicinais e seus derivados, é fundamental que os insumos sejam submetidos a ensaios que comprovem a veracidade dos seus compostos, bem como a análise de potenciais contaminantes. A atenção conferida ao controle de qualidade em farmácias de manipulação assume um papel crucial para assegurar a saúde do consumidor final.

As amostras apresentaram aspecto de pó fino e homogêneo, com odor e cor característicos de cada espécie. Os resultados do teor de umidade, granulometria, $\mathrm{pH}$ e densidade de todos os extratos analisados enquadram-se nos valores preconizados pela Farmacopeia Brasileira.

Quanto a solubilidade dos extratos secos, as amostras de capim-limão, carqueja e ginkgo foram classificadas como muito solúvel à água; castanha-da-índia, chapéu-de-couro, cúrcuma, kava-kava, melissa e passiflora revelaram-se parcialmente solúveis e o extrato de cavalinha se demonstrou parcialmente insolúvel ao solvente utilizado

Todos os extratos testaram positivo para flavonoides. Quanto à presença de saponinas, as amostras apresentaram resultado positivo, com exceção das alíquotas de ginkgo, kava-kava e passiflora. Em relação aos taninos, somente castanha-da-índia, cavalinha e gingko revelaram tanino em sua composição.

Nenhuma amostra apresentou contaminação por bactérias totais, Salmonella e Shiguella. Todas as alíquotas apresentaram crescimento de bolores e leveduras dentro dos valores farmacopéicos de referência.

Com estes resultados, conclui-se que os extratos secos de capim-limão, carqueja, castanha-da-índia, cavalinha, chapéu-de-couro, cúrcuma, ginkgo, kava-kava, melissa e passiflora utilizados na farmácia de manipulação de fitoterápicos analisada apresentam excelente qualidade e encontram-se dentro dos padrões de referência preconizados pela Farmacopeia Brasileira.

\section{Referências}

Andre, A. C. G. M., Silva, A. P. F. \& Vasconcelos, E. M. (2013). Caracterização Físico-química do Material Vegetal e dos Extratos de Cestrum laevigatum Schltdl (Solanaceae). Cadernos de Graduação - Ciências Biológicas e da Saúde Fits, 1(2),11-19.

Badke, M. R. et al. (2019). Panorama brasileiro dos serviços de plantas medicinais e fitoterápicos. Rev. Enferm. UFSM. 9(1), 1-19.

Barbosa, L. N. et al. (2009). Effects of Ocimum basilicum linn essential oil and sodium hexametaphosphate on the shelf life of fresh chicken sausage. Journal of Food Protection. 77(6), 981-986. 
Beltrame, F. L. et al. (2009). Avaliação da qualidade das amostras comerciais de Baccharis trimera L. (Carqueja) vendidas no Estado do Paraná. Acta Scientiarum. Health Sciences. 31(1),37-43, 2009.

Bonomo, M. G. et al. (2020). Antimicrobial Activity, Antioxidant Properties and Phytochemical Screening of Aesculus hippocastanum Mother Tincture against Food-borne Bacteria. Letters in Drug Design \& Discovery. 17(1), 48-56.

Brasil - Agência Nacional de Vigilância Sanitária -Anvisa (2019). Farmacopeia Brasileira. $6^{\mathrm{a} e d .}$

Brasil. Ministério da Saúde. Agência Nacional de Vigilância Sanitária. (2014). Resolução - RDC $n^{\circ}$ 26, de 13 de maio de 2014. Dispõe sobre o registro de medicamentos fitoterápicos e o registro e a notificação de produtos tradicionais fitoterápicos. Diário Oficial da União, Brasília, DF, 1,52.

Braz, P. et al. (2015). Análise microbiológica de preparações medicinais adquiridas em raizeiro na cidade de Sanclerlândia, Goiás. Revista Faculdade Montes Belos (FMB). 8(1),1-10.

Capra, R. S. et al. (2014). Preparados homeopáticos e ambiente de cultivo na produção e rendimento de quercetina em carqueja [Baccharis trimera (Less) DC.]. Revista Brasileira de Plantas Medicinais.16(3), 566-573.

Carvalho, E. S. et al. (2019). Endothelium-Dependent Effects of Echinodorus grandiflorus (Cham. \& Schltdl.) Micheli Mediated by M3-Muscarinic and B2Bradykininergic Receptors on Peripheral Vascular Resistance and Its Modulatory Effects on $\mathrm{K}+$ Channels in Mesenteric Vascular Beds. Evidence-Based Complementary and Alternative Medicine. 4(1), 1-12.

Colson, E. et al. (2019). Discrimination of Regioisomeric and Stereoisomeric Saponins from Aesculus hippocastanum Seeds by Ion Mobility Mass Spectrometry. J. Am. Soc. Mass Spectrom. 30(11), 2228-2237.

Correia, L. P. (2011). Obtenção e Padronização Química e Biológica de Pós de Plantas Medicinais de Diferentes Tamanhos de Partículas.. Dissertação (Programa de pós-graduação em Ciências Farmacêuticas) - Universidade Federal de Pernambuco, Recife.

Cortez, M. V. et al. (2020). Effect of heat and microwave treatments on phenolic compounds and fatty acids of turmeric (Curcuma longa L.) and saffron (Crocus sativus L.). Braz. J. Food Technol. 23(1) 1-9.

Garbin, L. et al. (2013). Avaliação da Qualidade de Plantas Medicinais Distribuídas por uma Unidade de Saúde de um Município do Interior do Paraná. Revista Ciências Exatas e Naturais. 15(1), 77-93.

Gonçalves, A. H. et al. (2015). Atividade fungitóxica in vitro dos óleos essenciais de Lippia sidoides Cham., Cymbopogon citratus (D.C.) Stapf. e de seus constituintes majoritários no controle de Rhizoctonia solani e Sclerotium rolfsii. Revista brasileira de plantas medicinais. 17(4), 1007-1015.

Haraguchi, L. M. M. et al. (2020). Impact of the Training of Professionals from São Paulo Public Health System in Phytotherapy Practice. Rev. bras. educ. med. 44, (1), 1-10.

Hellmann, M. A. \& Velasquez, L. G. (2017). Contaminação microbiológica em plantas medicinais e hortaliças e sua implicação no estado de saúde do consumidor: revisão. Arq. Cienc. Saúde UNIPAR. 21(2), 123-130.

Lacerda, D. S. \& Lionzo, M. (2011). Aspectos Atuais da Biodisponibilidade de Fármacos com Baixa Solubilidade: Um Enfoque Sobre a Sinvastatina. Infarma - Ciências Farmacêuticas. 23(6), 3-9.

Lorenzetti, E. R. et al. (2012) Controle da ferrugem das folhas do capim-limão [Cymbopogon citratus (DC.) Stapf] com produtos naturais. Revista brasileira de plantas medicinais.14(4), 1-12.

Melo, J. G. et al. (2007). Qualidade de produtos à base de plantas medicinais comercializados no Brasil: castanha-da-índia (Aesculus hippocastanum L.), capim-limão (Cymbopogon citratus (DC.) Stapf) e centela (Centella asiática (L.) Urban). Acta Botanica Brasilica. 21(1), 27-36.

Miraj, S., Kopaei, R. \& Kiani, S. (2016). Melissa officinalis L.: A Review Study With an Antioxidant Prospective. Journal of Evidence-Based Complementary \&Alternative Medicine. 22(3), 385-394.

Montes, R. A. et al. (2017). Qualidade Microbiológica de Drogas Vegetais Utilizadas na Fitoterapia Popular. Revista ESPACIOS. 38(11), 12-18.

Moreno, A. H. \& Abreu, M. C. (2019). Estudo Comparativo de Quatro Métodos Farmacotécnicos para Preenchimento de Cápsulas Gelatinosas Rígidas. Revista Brasileira Multidisciplinar-ReBraM. 22(2), 107-119.

Nowacki, L. C. et al. (2015). Analgesic effect of Hypericum perforatum, Valeriana officinalis and Piper methysticum for orofacial pain. Braz. J. Oral Sci. $14(1), 60-65$.

Ogava, S. E. N. et al. (2003). Implantação do programa de fitoterapia "Verde Vida" na secretaria de saúde de Maringá (2000-2003). Revista Brasileira de Farmacognosia. 13(1), 58-62.

Oliveira, O. W. \& Petrovick, P. R. (2010). Secagem por aspersão (spray drying) de extratos vegetais: bases e aplicações. Revista brasileira de farmacognosia. 20(4), 641-650.

Pereira, A. P. (2016). Controle de qualidade de amostras de cavalinha (Equisetum arvense L.) comercializadas no município de Palmas-TO. 2016. Trabalho de Conclusão de Curso (Curso de Bacharel em Farmácia) - Centro Universitário Luterano de Palmas.

Rodrigues, T. A. et al. (2020). A valorização das plantas medicinais como alternativa à saúde: um estudo etnobotânico. Revista Ibero Americana de Ciências Ambientais. 11(1), 411-428.

Sarto, D. A. Q. S. et al. (2018). Dry Extract of Passiflora incarnata L. leaves as a Cardiac and Hepatic Oxidative Stress Protector in LDLr-/- Mice Fed HighFat Diet. Brazilian Archives of Biology and Technology. 61(1), 1-10.

Silva, A. B. S. et al. (2018). Controle de qualidade em amostras de Calêndula officinalis. FACIDER Revista Científica. 11(1), 1-8. 
Research, Society and Development, v. 10, n. 8, e45710817557, 2021

(CC BY 4.0) | ISSN 2525-3409 | DOI: http://dx.doi.org/10.33448/rsd-v10i8.17557

Sociedade Brasileira De Farmacognosia - SBFgnosia. (2020). Flavonoides e Antocianos. http://sbfgnosia.org.br/Ensino/flavonoides_e_antocianinos.html. Acesso em: 18 ago. 2020.

Sociedade Brasileira De Farmacognosia - SBFgnosia. (2020). Saponinas. http://www.sbfgnosia.org.br/Ensino/saponinas.html. Acesso em: 18 ago. 2020.

Sofiati, F. T. (2009). Estudo fitoquímico e atividades biológicas preliminares de extratos de Polygonum acre H.B.K. (polygonaceae) e Synadenium carinatum BOISS (euphorbiaceae). 2009. Dissertação (Programa de pós-graduação em Ciências Farmacêuticas) - Faculdade de Ciências Farmacêuticas, Araraquara.

Uzomba, N. I., Obinna, A. \& Amaralam, E. (2020). Chinedu. Phytochemical and Nutritional Composition of Piper methysticum leaeves. World Journal of Pharmaceutical Research. 9(3), 220-226.

WANG, X. et al. (2020). In vitro anti-aging activities of ginkgo biloba leaf extract and its chemical constituents. Food Sci. Technol. 40(2), 476-482. 